Railway Engineering

Jan. 2022

Issue:15, Page: 170-181

Research Article

doi: 10.47072/demiryolu.1030152

http://dergipark.org.tr/demiryolu

e-ISSN: 2687-2463, ISSN: 2149-1607

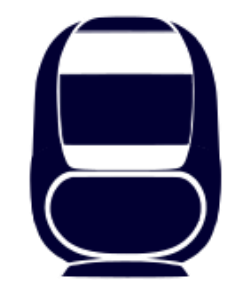

\title{
Monoray Sistemi Kent İçi Raylı Sistemlere Alternatif Olabilir mi?
}

\author{
Fatih YILDIZHAN $^{* 1}$ (D), Murat KARACASU²(D, Ömer Faruk RENÇBER ${ }^{3}$ (D) \\ ${ }^{1}$ Gaziantep Üniversitesi, Müh. Fak., İşaat Mühendisliği Bölümü, 27310, Gaziantep, Türkiye \\ ${ }^{2}$ Eskişehir Osmangazi Üniversitesi, Müh. Fak., İşsaat Mühendisliği Bölümü, 26480, Eskişehir Türkiye \\ ${ }^{3}$ Gaziantep Üniversitesi, İktisadi ve İdari Bil.Fak., İsletme Bölümü, 27310, Gaziantep, Türkiye \\ *fyildizhan@gantep.edu.tr
}

(Alınıs/Received: 30.11.2021, Kabul/Accepted: 13.01.2022, Yayımlama/Published: 31.01.2022)

Öz: Kent merkezlerinde sürdürülebilir ulaşım sağlayabilmek için toplu taşıma sistemini doğru planlanlamak gerekmektedir. Toplu taşıma sistemleri gelişen teknolojiye bağlı olarak çeşitliliğini arttırmış ve artan yolculuk talebine bağlı olarak optimum toplu taşıma sisteminin tercihi zorlaşmıştır. Son yıllarda monoray sisteminin raylı sistemlere alternatif olup olamayacağı da tartışma konusu olmuştur. Toplu taşımayla ilgili bir diğer tartışma konusu hangi sistemin optimum olduğunun hangi yöntemle karar verileceğidir. Toplu taşıma sistemlerine ekonomik değerlendirmeye göre karar verilmesi durumunda nitel kriterleri göz önünde bulundurmadığ için toplu taşımanın tüm etkilerini gösteremez ve bu durum toplu taşımadan istenilen düzeyde kullanımını engelleyebilir. Bu yüzden çok kriterli karar verme yöntemleri (ÇKKV), ekonomik değerlendirmede dikkate alınmayan nitel kriterleri de dikkate aldığı için toplu taşıma planlamasında yaygın olarak kullanılmaktadır. Fakat sadece ÇKKV'ye göre sistem seçilmesi ulusal ekonomi ve işletmeci kurumu açısından finansal problemlere yol açabilir. Bu çalışmada monoray sisteminin raylı sistemlere alternatif olma durumu ÇKKV'den PROMETHEE yöntemi ve monoray fizibilite çalışmaları birlikte ele alınarak incelenmiştir. Alternatifler monoray ve raylı sistemlerden tramvay, hafif raylı sistem ve metro olarak belirlenmiştir. Kriterler dört ana kriter ve 11 alt kriterden oluşturulmuştur. Eskişehir için yapılan monoray fizibilite etüdü çalışmasının sonuçları da ele alınarak ÇKKV-ekonomik değerlendirme ilişkisi incelenmiştir. Çalışmadan elde edilen sonuçlara göre birinci sırada monoray sistemi yer almaktadır. Çalışmanın bulguları monoray sisteminin sahip olduğu üstün özellikleri sayesinde raylı sisteme alternatif bir sistem olabileceğini göstermektedir. Monoray PROMETHEE yönteminde en iyi sistem görünmesine rağmen yapılan monoray sistemi ekonomik değerlendirmesinde uygulanabilir sonuçlar alınmamıştır. Ekonomik değerlendirmelerde uygulanabilir sonuçlar veren ve birçok belediye/karar verici kurum tarafindan tercih edilen tramvay sistemi ise PROMETHEE yönteminde en son sırada yer almaktadır. $\mathrm{Bu}$ bulgular ÇKKV veya ekonomik değerlendirmenin tek başına toplu taşıma sistemi seçimi ve planlanmasında yeterli olmayacağını, ikisinin beraber değerlendirilerek optimum sistemin seçilmesi gerektiğini gösterebilir.

Anahtar kelimeler: Monoray, Kent İçi Raylı Sistemler, Ekonomik Değerlendirme, PROMETHEE

\section{Could Monorail System be an Alternative to Urban Rail Systems?}

\begin{abstract}
In order to provide sustainable transportation in urban centers, it is necessary to design the public transportation system correctly. Public transportation systems have increased their variety depending on the developing technology and the choice of optimum public transportation system has become difficult due to the increasing travel demand. In recent years, it has been a matter of debate whether the monorail system could be an alternative to rail systems. Another debate with public transportation is how to decide which system is optimum. If the public transportation systems are decided according to the economic evaluation, it cannot show all the effects of public transportation and this situation may prevent the use of public transportation at the desired level since it does not take into account the qualitative criteria. Therefore, multi-criteria decision-making methods (MCDM) are widely used in public transportation planning, as they take into account the qualitative criteria that are not taken into account in the economic evaluation. However, choosing a system only according to the MCDM may cause financial problems for the national economy and the operating institution. In this study, the status of the monorail system as an alternative to rail systems has been investigated by taking the PROMETHEE method, one of the MCDM,
\end{abstract}


and monorail feasibility studies together. Alternatives were determined as monorail and tram, light rail transit and metro. The criteria were composed of four main criteria and 11 sub-criteria. The results of the monorail feasibility study for Eskişehir were also discussed and the MCDM-feasibility relationship was investigated. The monorail system is in the first rank in the results obtained from the study. The findings of the study show that the monorail system may be an alternative system to the rail system, thanks to its superior features. Although the monorail seems to be the best system in PROMETHEE method, no applicable results were obtained in the economic evaluation of the monorail system. The tram system, which gives feasible results in economic evaluations and is preferred by many municipalities/decisionmaking institutions, is in the last place in the PROMETHEE method. These findings may show that MCDM or economic evaluation alone could not be sufficient in the selection and planning of the public transportation system and that the optimum system should be selected by evaluating MCDM and economic evaluation together.

Keywords: Monorail, Urban Rail Systems, Economic Evaluation, PROMETHEE

\section{Giriş}

Hızlı ve plansız kentleşme ile olumsuz etkisini artıran otomobil kullanımı birçok kentte önemli bir ekonomik, sosyal ve çevresel sorun haline gelmiştir [1,2]. Ulaşım sektörü, toplam enerji tüketiminin \%29,6'sından, petrol tüketiminin \%50'sinden ve $\mathrm{CO}_{2}$ emisyonlarının \%27'sinden (Avrupa Birliği) sorumludur [3,4]. Çin'de hava kalitesini etkileyen faktörler (kentleşme, ekonomi ve ulaşım arasında) araştırmacılar tarafından incelenmiş ve en etkili faktörün ulaşım olduğu belirtilmiştir [1]. Kentlerde bu problemlerin temel sebebini otomobil kullanımı oluşturmaktadır. Bu nedenle sürdürülebilirlik temelli kentsel ulaşım planlarında otomobil kullanımının azaltılması mutlaka önceliklendirilmelidir [5]. Yaya ve bisiklet ulaşımı (aktif ulaşım modları) sürdürülebilir kentsel ulaşım planlamasında yer almalıdır [6-8]. Ancak şehirlerde artan mesafeler, zamandan tasarruf etme isteği ve birçok kentte bisiklet altyapısının olmaması bu ulaşım modlarının kullanımını azaltmaktadır $[9,10]$. Toplu taşıma sistemleri de sürdürülebilir kentsel ulaşım planlarında önemli bir yere sahiptir. Toplu taşıma sistemi kullanımın önündeki engel toplu taşıma sistemlerinin yetersiz olması ve düşük hizmet düzeyine sahip olmasıdır [11]. Bu üç kentsel ulaşım modunun birbirlerine entegre olması, ihtiyaç ve beklentilere uygun şekilde planlanması ve optimum toplu taşıma sisteminin seçilmesi gerekmektedir [11,12].

Artan yolculuk talebi ve gelişen teknoloji toplu taşıma sistemlerinin de çeşitliliğini arttırmış ve hangi sistemin optimum olduğunun belirlenmesi de zorlaşmıştır. Toplu taşıma sistemleri lastik tekerlekli sistemler, raylı sistemler ve özel sistemler olmak üzere üç sinıfa ayrılır [5]. Lastik tekerlekli sistemlere; dolmuş, minibüs, otobüs ve son yıllarda yaygınlaşan metrobüs örnek verilebilir. Metrobüs sahip olduğu ekonomik, güvenirlik, yüksek işletme hızı gibi özelliklerinden dolayı yüksek yolculuk taleplerinde tercih edilebilir bir sistem olabileceği son yıllarda yapılan çalışmalarla ifade edilmiştir $[13,14]$. Fakat yapımı için uygulanacak bölgede yeterli alan bulunmalıdır. Raylı sistemlere; tramvay, hafif raylı sistem (HRS), hafif metro ve metro örnek verilebilir. Tramvay, atlı omnibüslerin geliştirilmesi fikriyle oluşturulmuştur [9]. Elektrikli motor kullanımı ile ekonomik ve çevreci bir toplu taşıma seçeneği haline gelmiştir. Tramvay araç sayısına göre, nostaljik, cadde ve hızlı tramvay olmak üzere üç sınıfa ayrılmaktadır. HRS, 1960'larda tramvayların modernize edilmesiyle geliştirilmiştir ve tramvay ile metro arasında değerlendirilebilecek bir raylı sistemdir [15]. Metro, ilk olarak 1863 y1lında Londra'da aç-kapa yöntemi ile kullanılmıştır [16]. Şehir ölçeğinde en fazla insanı ve en hızlı şekilde taşıyabilen en gelişmiş raylı sistemdir. Özel sistemlere örnek olarak teleferik ve monoray örnek verilebilir. Monoray sistemi çoğunlukla yerden yüksekte çelik veya betonarme hat üzerinde ilerleyen lastik tekerlekli bir toplu taşıma sistemidir [17]. Monoray raylı sistemlere göre yüksek eğim çıkabilme, kolay projelendirme gibi avantajlara sahiptir [18-20]. Bu avantajları birçok araştırmacının dikkatini çekmiş ve raylı sistemlere alternatif bir sistem olabileceği belirtilmiştir [21,22]. Bazı araştırmacılarda monorayın görsel amaçlarla kullanılabilecek bir sistem olduğunu toplu taşımaya uygun olmadığını belirtmiştir [23]. Monorayın (Japonya, Almanya ve Çin hariç) birçok ülkede 
raylı sistemler kadar tercih edilmemesi [17], raylı sistemler alternatif bir sistem olabileceği konusunda tartışmaları devam ettirmektedir.

Güzergâh üzerinde optimum toplu taşıma sisteminin seçilmemesi durumunda bu hatanın telafi edilmesi çok zordur. Çünkü toplu taşıma sistemlerinin başka bir sistemle değiştirilmesi ekonomik, finansal ve sosyal sorunlara neden olabilir [24]. Örneğin yapılan çalışmada, yetersiz hizmet düzeyine sahip olan cadde tramvayı yerine monoray planlanmış, değerlendirme süreci sonunda (27 yıl) ülke ekonomisine 25 milyon dolar, yatırımcı/işletici kurumlara 215 milyon dolar zarar verebileceği belirilmiştir [17]. Ancak doğru planlanmış toplu taşıma, bir şehre kültürel, sosyal ve ekonomik açıdan önemli katkılar sağlayabilir. Örneğin, raylı toplu taşıma sistemi inşa etmenin otomobil enerji tüketimini $\% 5,5$ ve kişi başına otomobil enerji tüketimini $\% 6,6$ oranında azaltabileceği belirtilmiştir [3]. Başka bir çalışmada ise metro projesinin değerlendirme süreci sonunda (27 yıl) çevresel kazanım olarak 17 milyon dolar, zaman tasarrufu olarak ise 1,3 milyar dolar katkıda bulunabileceği belirtilmiştir [25]. Toplu taşıma sistemleri değerlendirilirken karzarar durumlarını gösteren ekonomik (ulusal ekonomi açısından) ve finansal (yatırımcı/işletme kurum açısından) fizibilite çalışmaları yapılmalıdır [5,19]. Ancak bir sistemin uygulanabilir sonuçlar vermesi gerekli olmakla birlikte, bu fizibilite çalışmaları tek başına yeterli olmayabilir. Öncelikle hangi sistemin seçileceğine doğru karar verilmesi, ardından toplu taşıma sistemleri için fizibilite çalışmaları yapılması daha doğru sonuçlar verebilir. Bu şekilde toplu taşıma planlanması yapılırsa daha verimli sonuçlar alınabilir. Ek olarak, fayda-maliyet $(B / C)$, net bugünkü değer (NPV), iç getiri oranı (IRR) vb. gibi fizibilite çalışmaları sonuçları genellikle bir projenin tüm etkilerini göstermez [26,27]. Bu nedenle çok kriterli karar verme yöntemleri (ÇKKV), fizibilite çalışmalarında dikkate alınmayan nitel kriterleri de dikkate aldığı için toplu taşıma planlamasında yaygın olarak kullanılmaktadır [28]. Literatürde ÇKKV'nin ekonomik ve mali fizibilite çalışmalarıyla birlikte kullanılması gerektiği ve bu konuda daha fazla çalışma yapılması gerektiği belirtilmiştir [27].

Literatürdeki detaylı fizibilite çalışmalarından biri Eskişehir için iki ayrı güzergâh için planlanan monoraydır. Çalışmada düşük hizmet düzeyine sahip cadde tramvayı ve otobüs hattı olmak üzere iki ayrı hat için monoray önerilmiştir [17]. Ancak sonuçlar monorayın hem ülke ekonomisi hem de yatırımcı/işletme kurumları için uygulanabilir sonuçlar vermediğini göstermiştir. Fizibilite çalışmasının yanı sıra, toplu taşıma projelerinde ÇKKV uygulamasının yapılması doğru tercih açısından ve literatürdeki eksikliği gidermesi açısından değerlidir. Buna ek olarak raylı sistemlere göre daha az tercih edilen monorayın raylı sistemlere alternatif olabilirliği de dikkate alınması gereken bir diğer konudur. Bu çalışmada ilk kez ÇKKV, fizibilite çalışması arasındaki ilişki araştırılmıştır. Fizibilite sonuçlarını tamamlamak için ÇKKV'lerden PROMETHEE yöntemi kullanılarak monoray sistemi ve kentsel raylı sistemler karşılaştırılmıştır. Alternatifler monoray, tramvay, HRS ve metro olarak belirlenmiştir. Kriterler maliyetler, hat-araç özellikleri, kullanıcı memnuniyeti ve çevresel etki olarak belirlenmiştir. Böylece PROMETHEE sonuçlarının ve fizibilite çalışmasının tutarlılığı incelenmiştir. Ayrıca fizibilite çalışmalarının yanı sıra PROMETHEE kullanılarak monoray sisteminin raylı sistemlere alternatif olma durumu değerlendirilmiştir.

\section{Eskişehir Monoray Fizibilite Etüdü}

Eskişehir, 888.828 nüfusu ve üç üniversitesiyle yolculuk talebi yüksek bir şehirdir. Eskişehir için yapılan monoray fizibilite çalışmasında iki hat incelenmiştir [17] ve Şekil 1 bu hatları göstermektedir. Bu hatlardan ilki güzergâh üzerinde Anadolu Üniversitesi, hastane, otogarın bulunduğu ve buna bağlı olarak talebin yoğun olduğu SSK-Otogar hattıdır. Bu hatta $1000 \mathrm{~mm}$ ray açıklığına sahip ve tek araçtan oluşan cadde tramvayı bulunmaktadır. Kapasite, konfor ve güvenilirlik açısından yetersiz kalmaktadır [5]. İkinci hat olarak Eskişehir Teknik Üniversitesi'nin bulunduğu Gaffar Okkan-ESTÜ hattı incelenmiştir. Şuan otobüsle işletilen bu hat için tramvay yapım çalışmaları başlamış ve bitmek üzeredir Bu iki hatıın bilgileri Tablo 1'de verilmektedir. 


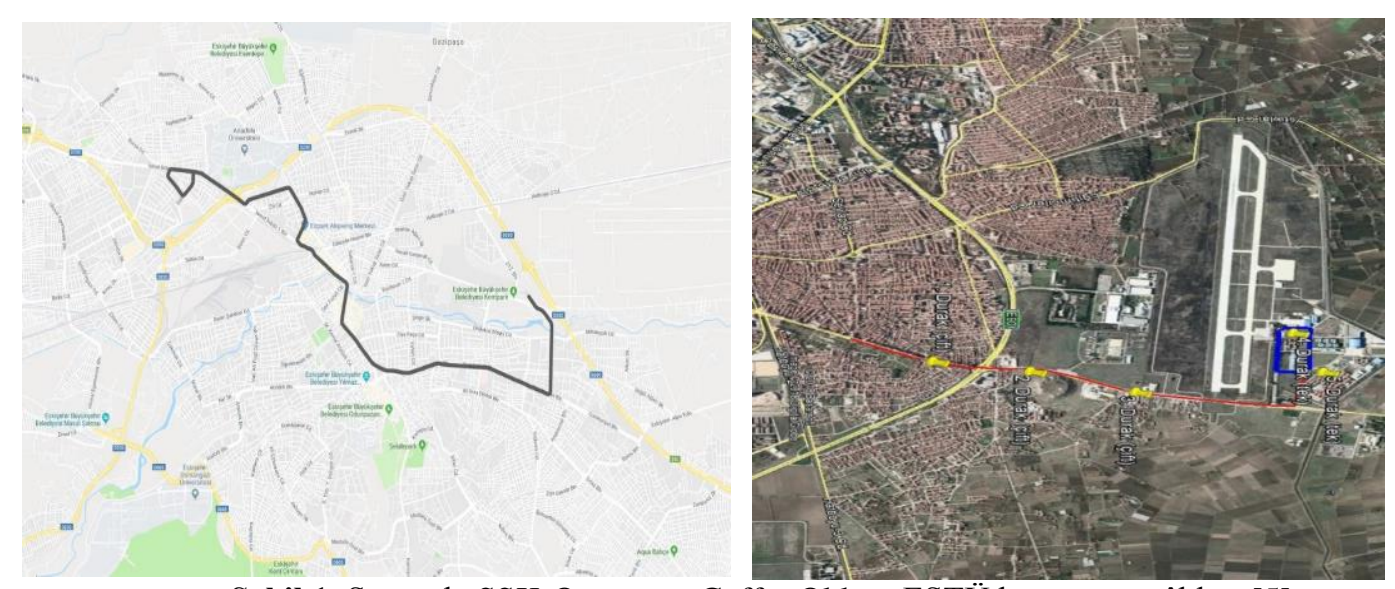

Şekil 1. Sırasıyla SSK-Otogar ve Gaffar Okkan-ESTÜ hattı güzergâhları [5]

Tablo 1. Hat bilgileri [17]

\begin{tabular}{lll}
\hline Hat Bilgileri & SSK-Otogar & Gaffar Okkan-ESTÜ \\
\hline Hat Uzunluğu $(\mathrm{km})$ & 10,5 & 4 \\
2021 Günlük Yolcu Sayıs1 & 45.471 & 24.560 \\
2045 Günlük Yolcu Sayıs1 & 54.609 & 60.575 \\
\hline
\end{tabular}

SSK-Otogar hattı daha uzundur ve ilk yıllarda yolcu sayısı daha yüksektir. Gaffar Okkan-ESTü hattın için değerlendirme süreci sonunda (2045 yılı) yolcu sayısının daha fazla olması beklenmektedir. Eskişehir için yapılan monoray fizibilite etüdünde ekonomik fizibilite ve finansal fizibilite etüdleri hazırlanmıştır. Fizibilite etüdü sonuçları Tablo 2'de verilmektedir. Maliyetler, yapım maliyetleri, araç maliyetleri ve işletme\&bakım maliyetlerinden oluşmuştur. Betonarme hat olarak düşünülen monorayın km başına yapım maliyeti 20,16 milyon \$ olarak hesaplanmıştır.

Tablo 2. Fizibilite etüdü sonuçları[17]

\begin{tabular}{lllll}
\hline \multirow{2}{*}{ Fizibilite Etüdü Sonuçları } & SSK-Otogar & \multicolumn{3}{l}{ Gaffar Okkan-ESTÜ } \\
\cline { 2 - 5 } & Ekonomik & Mali & Ekonomik & Mali \\
\hline Net Bugünkü Değer & $\$-25.282 .615$ & $\$-214.876 .105$ & $\$-24.485 .247$ & $\$-71.335 .743$ \\
Fayda/Maliyet Oranı & 0,86 & 0,20 & 0,69 & 0,38 \\
İç Verimlilik Oranı & $\% 7,68$ & $-5,24 \%$ & $\% 5,93$ & $-0,33 \%$ \\
\hline
\end{tabular}

Araçlar SSK-Otogar güzergâhında dört orta büyüklükte vagondan oluşan monoray setleriyle hesaplanmış (kapasite 580 yolcu) ve set maliyeti 5 milyon \$ olarak alınmıştır. Araçlar Gaffar Okkan-ESTÜ güzergâhında dört küçük vagondan oluşan monoray setleriyle hesaplanmış (kapasite 280 yolcu) ve set maliyeti 3 milyon \$ olarak alınmıştır. İşletme\&bakım maliyeti km başına SSK-Otogar için 5,7 \$ ve Gaffar Okkan-ESTÜ için 5,3 \$ olarak alınmıştır. Duraklar yakın olduğu için monorayın işletme hızı minimum değer olan $25 \mathrm{~km} / \mathrm{sa}$ olarak alınmıştır. Projenin ulusal ekonomi açısından faydaları, tramvay/otobüs yatırım maliyetlerinde azalma, tramvay/otobüs işletme maliyetlerinde azalma, çevresel etki maliyetlerinde azalma, yol bakım maliyetlerinde azalma, kaza maliyetlerinde azalma ve yolculuk zamanı kazançlarının ekonomik değerinden oluşmaktadır. Projenin yatırımcı/işletmeci kurum açısından gelirleri bilet ve reklam gelirleridir [17].

\section{PROMETHEE Yöntemi}

PROMETHEE yönteminin uygulanması şu sırayla yapılmaktadır:

Adım 1: Karar matrisinin oluşturulması

Adım 2: Tercih fonksiyonlarının belirlenmesi

Adım 3: Alternatif çiftler arasında tercih indeksi oluşturulması 
Adım 4: Pozitif ve negatif üstünlüklerin belirlenmesi

Adım 5: Promethee I- $(\Phi+)(\Phi-)$ çözümlerinin bulunması

Adım 6: Promethee II-Nihai üstünlüklerin belirlenmesi

Birçok ÇKKV tekniğinde olduğu gibi analiz aşaması karar matrisinin oluşturulması ile başlamaktadır. Bu matriste alternatifler ve kriterler Tablo 3 'te olduğu gibi açıkça belirtilmektedir. PROMETHEE yönteminde diğer ÇKKV yöntemlerinden farklı olarak, tercih fonksiyonları belirlenmektedir. Buna göre, aşağıda yer alan tabloda belirtilen bir fonksiyon seçilmekte ve kriterler ile alternatifler bu fonksiyonlara göre değerlendirilmektedir.

Tablo 3. PROMETHEE Tercih Fonksiyonları [29]

\begin{tabular}{|c|c|c|c|c|c|}
\hline Tip & Fonksiyo & & & Parametre & Kullanım Amacı \\
\hline $\begin{array}{l}\text { Birinci Tip } \\
\text { (Olağan) }\end{array}$ & $P(x)=$ & $\left\{\begin{array}{l}0 \\
1,\end{array}\right.$ & $\left.\begin{array}{l}x \leq 0 \\
x>0\end{array}\right\}$ & - & $\begin{array}{l}\text { Kriterler için herhang } \\
\text { bir tercih söz konusu } \\
\text { olmadığ } 1 \text { durumda }\end{array}$ \\
\hline $\begin{array}{l}\text { İkinci Tip } \\
\text { (U-Tipi }\end{array}$ & $P(x)=$ & $\left\{\begin{array}{l}0, \\
1,\end{array}\right.$ & $\left.\begin{array}{l}x \leq 1 \\
x>1\end{array}\right\}$ & 1 & $\begin{array}{l}\text { Kriterlerin bir } \\
\text { parametre değerinden } \\
\text { yüksek olmas1 tercih } \\
\text { edildiği durumda }\end{array}$ \\
\hline $\begin{array}{l}\text { Üçüncü Tip } \\
\text { (V Tipi) }\end{array}$ & $P(x)=$ & $\begin{array}{l}\frac{x}{m}, \\
1,\end{array}$ & $\left.\begin{array}{l}\mathrm{x} \leq m \\
\mathrm{x}>m\end{array}\right\}$ & $\mathrm{m}$ & $\begin{array}{lr}\text { Kriterlerin } & \text { bi } \\
\text { ortalamaya } & \text { göre } \\
\text { değerlendirilip } & \text { bu } \\
\text { değerin altındak } \\
\text { değerler de ihma } \\
\text { edilmek istenmiyorsa }\end{array}$ \\
\hline $\begin{array}{l}\text { Dördüncü } \\
\text { Tip } \\
\text { (Seviyeli) }\end{array}$ & $P(x)=$ & $\begin{array}{l}0, \\
\frac{1}{2} \\
1,\end{array}$ & $\left.\begin{array}{l}\mathrm{x} \leq q \\
q<x \leq q+p \\
x>q+p\end{array}\right\}$ & $\mathrm{q}, \mathrm{p}$ & $\begin{array}{l}\text { Kriterler için belirli bi } \\
\text { değer } \\
\text { belirlenecekse }\end{array}$ \\
\hline $\begin{array}{l}\text { Beşinci Tip } \\
\text { (Lineer) }\end{array}$ & $P(x)=$ & $\left\{\begin{array}{l}0, \\
\frac{x-s}{r} \\
1\end{array}\right.$ & $\left.\begin{array}{c}\mathrm{X} \leq s \\
s \leq x \leq s+r \\
x \geq s+r\end{array}\right)$ & $\mathrm{s}, \mathrm{r}$ & $\begin{array}{l}\text { Kriterlerin içerisinden } \\
\text { ortalama üstündek } \\
\text { değerleri tercih etme } \\
\text { durumunda }\end{array}$ \\
\hline $\begin{array}{l}\text { Altınc1 Tip } \\
\text { (Gaussian) }\end{array}$ & $P(x)=$ & $\left\{\begin{array}{l}0, \\
1-e^{-x^{2} / 2 \sigma^{2}}\end{array}\right.$ & $\left.\begin{array}{c}\mathrm{x} \leq 0 \\
x \geq 0\end{array}\right\}$ & $\sigma$ & $\begin{array}{l}\text { Kriterleri ortalamadan } \\
\text { sapmaya göre terci } \\
\text { etmek istediği durumda }\end{array}$ \\
\hline
\end{tabular}

Tercih fonksiyonları belirlendikten sonra alternatifler karşılaştırılır. Pozitif ve Negatif üstünlükler değerlendilir.

Aşağıdaki verilen durumlardan herhangi biri sağlanıyorsa a alternatifi $b$ alternatifine tercih edilir;

$\begin{array}{lll}\Phi+(a)>\Phi+(b) & \text { ve } & \Phi-(a)<\Phi-(b) \\ \Phi+(a)>\Phi+(b) & \text { ve } & \Phi-(a)=\Phi-(b) \\ \Phi+(a)=\Phi+(b) & \text { ve } & \Phi-(a)<\Phi-(b)\end{array}$

Aşağıdaki durumda a alternatifi ile $\mathrm{b}$ alternatifi farksızdır;

$\Phi+(\mathrm{a})=\Phi+(\mathrm{b}) \quad$ ve $\quad \Phi-(\mathrm{a})=\Phi-(\mathrm{b})$

Aşağıdaki durumda herhangi biri sağlanıyorsa a alternatifi $b$ alternatifi ile karşılaştırılamaz;

$\Phi+($ a) $>\Phi+($ b) $\quad$ ve $\quad \Phi-(a)>\Phi-(b)$ 
$\Phi+$ (a) $<\Phi+$ (b) ve $\quad \Phi-(a)<\Phi-(b)$

Bir sonraki adımda kıyaslamaya esas alınan $\Phi$ değeri hesaplanır. Hesaplanan net $\Phi$ öncelik değerlerine göre bütün alternatifler değerlendirilir.

$\Phi(\mathrm{a})=\Phi+(\mathrm{a})-\Phi-(\mathrm{a})$

Bulunan net öncelik değerine göre;

$\Phi(\mathrm{a})=\Phi(\mathrm{b})$ ise a alternatifi b alternatifinden farksizdir,

$\Phi(\mathrm{a})>\Phi(\mathrm{b})$ ise a alternatifi b alternatifine göre daha üstündür. Karar vericinin bu iki alternatif arasinda a alternatifini tercih etmesi beklenmektedir.

Çalışmada kapsamında kriterler ve alternatifler Visual Promethee yazılımı ile Promethee tekniğine göre değerlendirilmiştir. Visual Promethee, Mareschal ve ekibi tarafından 2014 yılında geliştirilen ve Promethee yönteminin uygulanmasına yönelik olan bir yazılımdır. Yöntemin uygulamasında Tablo 3'te belirtilen tercih fonksiyonlarından altınc1 tip Gaussian tercih fonksiyonu kullanılmıştır. Bunun nedeni, verilerin ortalama ve standart sapmaya göre değerlendirilmesinin daha uygun olacağının düşünülmesidir. Ayrıca, alternatifler arası yüksek düzey nümerik farklılıkların nihai sıralamayı çok fazla etkilememesi amaçlanmıştır.

\subsection{Alternatiflerin belirlenmesi}

Monoray sistemi ilk alternatif olarak belirlenmiştir. Monoray, betonarme veya çelik tek bir hattın üzerinde asılı (asma tip) veya altında (çatı tipi) hareket eden bir toplu taşıma sistemidir [18,30]. Araçlarının tekerlekleri lastiktir ve çoğunlukla yer üstünde hareket ederler [5]. Monoray sistem örneği Şekil 2'de gösterilmektedir. Japonya, Almanya ve Çin başta olmak üzere birçok ülkede bulunmaktadır. Son yıllarda gelişmekte olan ülkelerde de (Malezya gibi) tercih edilmektedir ancak kent içi raylı sistemlere kıyasla daha az örnek bulunmaktadır [17].

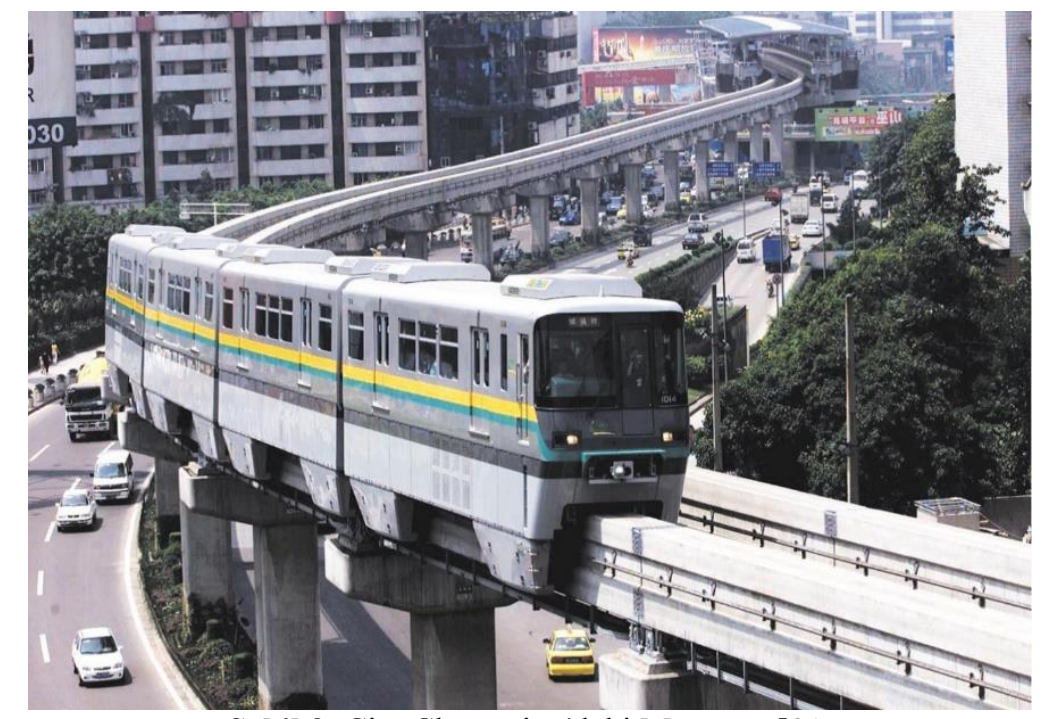

Şekil 2. Çin, Chongqing'deki Monoray [31]

Kent içi raylı sistemlerden tramvay, HRS ve metro alternatif olarak belirlenmiştir. Kent içi raylı sistemler; dolmuş, minibüs ve otobüs gibi sistemlere göre güvenlik, dakiklik, yüksek verimlilik ve çevre dostu olma gibi avantajlara sahiptir [32].

\subsection{Kriterlerin belirlenmesi}

Kriterlerin belirlenmesinde literatürdeki çalışmalar dikkate alınmıştır [17,26,33]. Bunlar maliyetler, hat ve araç özellikleri, müşteri memnuniyeti ve çevresel etki olmak üzere dört ana kriter belirlenmiştir. Dört kriter ayrıca birkaç alt kritere ayrılmıştır. 
"Maliyet" faktörünün üç alt kriteri şu şekildedir:

- "İnşaat maliyeti", projenin yapımına ilişkin altyapı, elektrik-mekanik sistemler ve mühendislik hizmetleri gibi maliyetleri ifade eder.

- "Araç maliyeti”, sistemin işletme süresi boyunca ihtiyaç duyduğu birim araç maliyetlerini ifade eder.

- "İşletme ve bakım", sistemin işletilmesi ve bakımı için gereken maliyetleri ifade eder.

"Hat ve araç karakterizasyonu" faktörünün dört alt kriteri şu şekildedir:

- "Kapasite", sistemin bir yönde taşıyabileceği maksimum yolcu sayısını ifade eder.

- "Esneklik", sistemin talep veya rotalardaki değişiklikler gibi değişkenliklere yanıt verebilme esnekliğini ifade eder.

- "Işsletme hızı", araçların çalışması sırasında yavaşlama, hızlanma, bekleme vb. tüm hareketleriyle ortalama hızı ifade eder.

- "Güvenilirlik", aracın zamanında varış ve ilerleme düzenliliği anlamına gelir.

Müşteri memnuniyeti faktörünün iki alt kriteri şu şekildedir:

- "Güvenlik", yolculara zarar verebilecek bir kazadan korunma derecesini ifade eder.

- "Konfor", yolcuların seyahat esnasındaki fiziksel ve duygusal konforunu ifade eder.

Çevresel etki faktörünün iki alt kriteri şu şekildedir:

- "Hava kirliliği”, araçların yolcu-km başına ürettiği $\mathrm{CO}_{2}$ değerini ifade eder.

- "Gürültü kirliliği”, araçların (dBA) cinsinden gürültü değerini ifade eder.

Monoray ve şehir içi raylı ulaşım sistemlerinin özellikleri Tablo 4'te verilmektedir. Monorayın 4 araç, tramvay 1 araç, HRS 4 araç ve metro 8 araçtan oluştuğu dikkate alınarak hesaplamalar yapılmıştır. Maliyetler Eskişehir, Bursa ve İstanbul fizibilite çalışmalarından alınmıştır [17,24,25,34]. Tramvay için Eskişehir'deki işletme hızı dikkate alınmıştır [5]. Diğer sistemler için çalışmadaki min-maks değerlerinin ortalaması alınarak çalışma hızı hesaplanmıştır [35]. Kapasite hesaplamalarında, monoray için minimum sefer sıklığ 2 dakika, tramvay için 5 dakika, HRS için 3 dakika ve metro için $3 \mathrm{dk}$ olarak alınmıştır. Tramvay kavşak noktalarında taşıyolu ile kesiştiği için bulunduğu güzergâh daha sık sefer sayısına izin vermemektedir [5]. Esneklik, güvenilirlik, güvenlik ve konfor faktörleri literatürdeki derecelendirmelere dayanmaktadır [16,36]. Çevresel etki değerleri literatürdeki çalışmalardan alınmıştır $[37,38]$.

Tablo 4. Monoray ve kentsel raylı ulaşım sisteminin özellikleri

\begin{tabular}{|l|l|l|l|l|l|l|l|l|l|l|l|}
\hline Kriterler & $\begin{array}{l}\text { Yapım } \\
\text { M. }\end{array}$ & $\begin{array}{l}\text { Araç } \\
\text { M. }\end{array}$ & $\begin{array}{l}\text { İ.\&B. } \\
\text { M. }\end{array}$ & $\begin{array}{l}\text { İşletme } \\
\text { H. }\end{array}$ & Kap. & Esnek. & $\begin{array}{l}\text { Güve- } \\
\text { nirlik }\end{array}$ & $\begin{array}{l}\text { Güven- } \\
\text { lik }\end{array}$ & Konfor & $\begin{array}{l}\text { Hava } \\
\text { K. }\end{array}$ & $\begin{array}{l}\text { Gürül } \\
\text { tü K. }\end{array}$ \\
\hline $\begin{array}{l}\text { Alternatif- } \\
\text { ler/ } \\
\text { Birim }\end{array}$ & $\begin{array}{l}\text { Milyon } \\
\$ / \mathrm{km}\end{array}$ & $\begin{array}{l}\text { Milyon } \\
\$ / \text { Set }\end{array}$ & $\begin{array}{l}\$ \text { Araç- } \\
\text { Km/Ka } \\
\text { pasite }\end{array}$ & Km/sa & $\begin{array}{l}\text { Yolcu/ } \\
\text { sa/yön }\end{array}$ & $X$ & $X$ & $X$ & $X$ & $\begin{array}{l}\text { g/yolcu } \\
- \text { km }\end{array}$ & dBA \\
\hline Monoray & 20,2 & $\$ 5,00$ & 0,010 & 32,5 & 17400 & 1 & 4 & 5 & 4 & 23,6 & 75 \\
\hline Tramvay & 3,2 & $\$ 2,85$ & 0,019 & 17 & 3000 & 3 & 1 & 3 & 3 & 22 & 90 \\
\hline HRS & 18 & $\$ 11,40$ & 0,008 & 29 & 20000 & 1 & 4 & 5 & 4 & 22 & 90 \\
\hline Metro & 44 & $\$ 12,80$ & 0,007 & 42,5 & 37400 & 1 & 4 & 5 & 4 & 22 & 90 \\
\hline
\end{tabular}


Yapım maliyetleri, yapım süresi ve hat uzunluğuna bağlıdır ve minimum düzeyde olmalıdır. Metronun birçok kentte tercih edilmemesinin sebebi yüksek yapım maliyetidir. Araç maliyetlerinin minimum olması aynı zamanda kapasitenin yüksek olması gerekir. İ\&B maliyetleri işletme süresince maliyet getirdiği için minimum değerde olmalıdır. İşletme hızının fazla olması araç sayısı ve müşteri memnuniyetini doğrudan etkilemektedir. Kapasitenin yüksek olması özellikle zirve saatlerde talebi karşılama açısından gereklidir. Esneklik, güvenirlik, güvenlik ve konforun iyi seviyede olması toplu taşımanın istenilen düzeyde kullanılması için önemlidir. Hava ve gürültü kirliliği minimum düzeyde olması çevresellik açısından çok değerlidir.

\section{Bulgular}

Uygulama neticesinde elde edilen pozitif ve negatif üstünlüklere ilişkin Phi skorları Tablo 5'te verilmektedir. Çalışmada elde edilen sonuçlara ve Tablo 5'e göre, monoray diğer alternatiflere göre en tercih edilebilir, tramvay ise tercih edilebilirliği en düşük sistem olarak değerlendirilmektedir.

Tablo 5. Alternatiflere ilişkin pozitif ve negatif üstünlük skorları

\begin{tabular}{llll}
\hline Alternatifler & Phi & Phi+ & Phi- \\
\hline Monoray & 0,1003 & 0,2770 & 0,1766 \\
Metro & $-0,0128$ & 0,2053 & 0,2182 \\
HRS & $-0,0205$ & 0,1823 & 0,2028 \\
Tramvay & $-0,0670$ & 0,2040 & 0,2709 \\
\hline
\end{tabular}

Ancak Eskişehir için yapılan monoray sistemi fizibilite etüdünde iki hat içinde uygulanabilir sonuçlar alınamamıştır. PROMETHEE tekniği sonuçlarına göre en tercih edilebilir alternatif monoray olsa da fizibilite etüdü sonuçlarına göre ilk hat olan SSK-Otogar hattına monoray planlanması durumunda ulusal ekonomiyi 25 milyon dolar, işletmeci kurumu 215 milyon dolar zarara uğratabileceği hesaplanmıştır [17]. PROMETHEE yöntemi sonuçlarına göre monorayın ardından, metro ve HRS gelmektedir. Metro yüksek maliyeti sebebiyle orta ölçekli şehirler için uygun olmamaktadır. HRS tramvayın geliştirilmesiyle oluşan bir sistem olarak tramvaya göre birçok özelliği daha avantajlıdır. Tramvay tercihi ise seçenekler içerisinden tercih edilebilirliği en düşük olarak bulunmuştur. Eskiş̧ehir'de SSK-Otogar hattındaki mevcut cadde tramvayının yeterli hizmet düzeyine sahip olmaması bu çalışmanın bulgularıyla uymaktadır [5]. Bu sonuçlar ÇKKV veya fizibilite etüdlerinin tek başına yeterli olmayacağını bütüncül bir yaklaşımla ele alınması gerektiğini gösterebilir. Şekil 3'te Visual PROMETHEE programı kullanılarak GAIA analizi sonuçları gösterilmektedir.

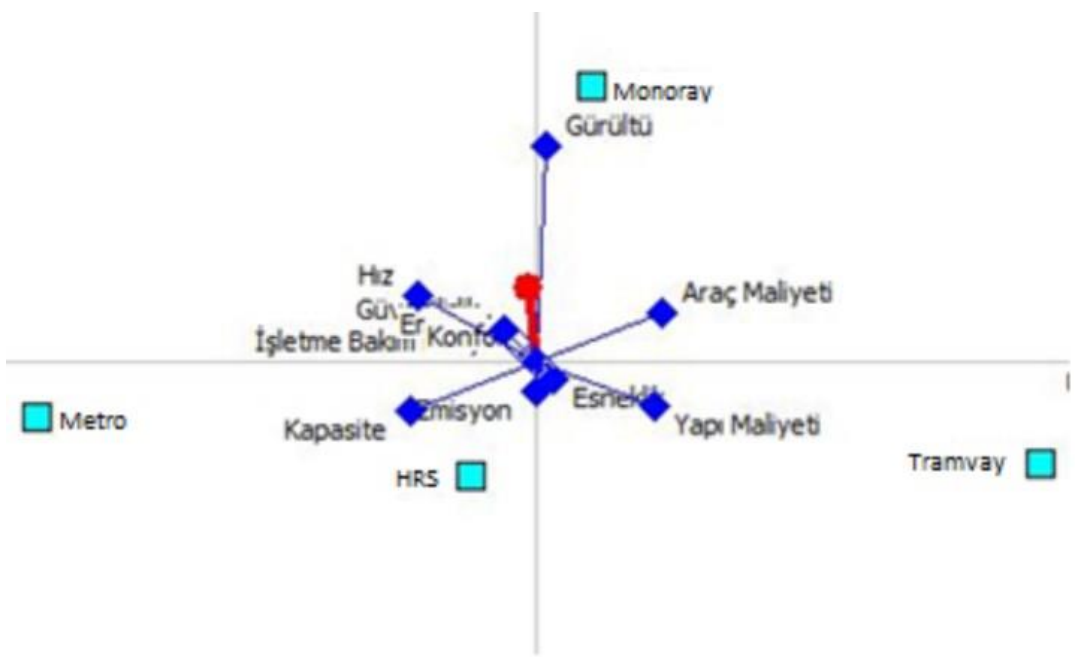

Şekil 3. Alternatif ve Kriterlere ilişkin GAIA Düzlemi 
Şekil 3'te görüldügü üzere monoray, araç maliyeti ve gürültü; tramvay, yapım maliyeti; metro ve HRS ise emisyon ve kapasite açısından tercih edilebilirdir. Genel olarak değerlendirildiği durumda ise, monorayın diğer alternatiflerden daha çok tercih edilebilir olduğu görülmektedir. Ayrıca şekle göre, monoray ulaşım sisteminin diğerlerine göre üstün yönünün "gürültü" kriteri olduğu da söylenebilir. Araçların tekerleklerinin lastik olması gürültü değerinde avantaj sağlamaktadır. Alternatiflerin üstün ve zayıf yönleri Şekil 4'te gösterilmektedir.

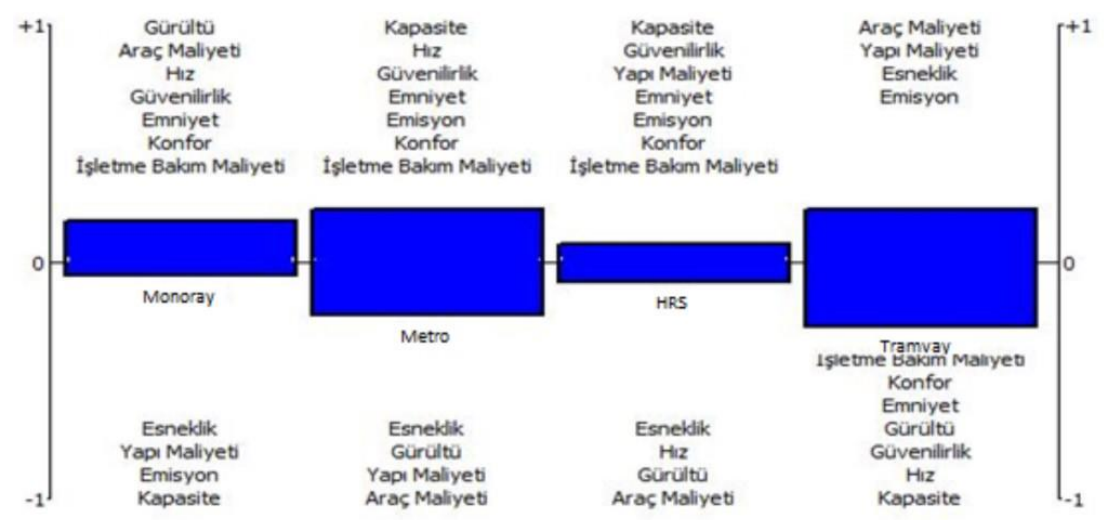

Şekil 4. Alternatiflere göre kriterlerin değerlendirilmesi

Şekil 4'te görüldüğü üzere kriterlerin eşit önemde alındığı uygulama neticesinde, monorayın gürültü, araç maliyeti, hız, güvenilirlik, emniyet, konfor ve işletme bakım maliyeti açısından üstün; esneklik, yapı maliyeti, emisyon ve kapasite açısından zayıf olduğu görülmüştür. Lastik tekerleklerinden kaynaklı sürtünmenin daha fazla olmasından dolayı enerji tüketimi ve emisyon değeri daha yüksektir. Güzergâha göre yükseltilmiş yapılar inşa ediliği için esnekliği düşüktür. Fakat 4 araçlık orta boy monoray seti yerine 8 araçlık büyük monoray araçlarından oluşan setlerde kapasite yükselebilir. Buna rağmen monoray diğer alternatifler içerisinden en çok tercih edilebilir seçenek olarak dikkat çekmektedir. Bu bulgular monorayın raylı sistemlere alternatif bir sistem olabileceğini göstermektedir. Metronun sahip olduğu üstün hat ve araç karakterizasyonu özelliklerine rağmen yüksek maliyetleri sebebiyle ikinci sırada yer almaktadır. HRS, tramvay ve metro arasında değerlendirilebilecek bir sistemdir. Tramvay ise araç ve yapım maliyeti ile esneklik ve emisyon özelliklerine göre üstün iken diğer kriterlere göre zayıf olarak değerlendirilmektedir. Bu da alternatifin tercih edilebilirliğini negatif yönde etkilemektedir. SSKOtogar hattındaki tramvayın düşük kapasite, konfor ve güvenilirliğe sahip olmasından kaynaklı problemler bu çalışmanın bulgularının tutarlığını göstermektedir [5]. Tramvay maliyet konusunda diğer sistemlere göre avantajlı olup ekonomik-mali fizibilite çalışmalarında uygulanabilir sonuçlar vermiş olması belediye/karar verici kuruluşlar için yeterli olabilir. Fakat sadece ekonomik-mali değerlendirmelerle toplu taşıma sisteminin seçilmesi istenilen düzeyde toplu taşıma kullanımı artırıp, otomobil kullanımı azaltmayabilir. Bu bulgular sadece ekonomik-mali fizibilite etüdüne göre toplu taşıma sistemi seçilmesinin yeterli olmadığına kanıt olabilir.

Ayrıca kriterlerin eşit öneme sahip olmadığı durumlarda, tüm sıralamalar değişebilir. Belediye/karar verici kuruluşlar, ilk olarak yolcuların ihtiyaç ve beklentilerine göre kriter ağırlıklarını belirleyerek optimum toplu taşıma sistemlerini nitel kriterlerini de dikkate alarak ÇKKV ile belirlemelidir. İkinci olarak ekonomik-mali fizibilite etüdleriyle değerlendirme yapılması toplu taşımadan istenilen faydaların sağlanmasını ve buna ek olarak ulusal ekonomiişletmeci kurum açısından önemli kazanımlar elde edilmesini sağlayabilir. ÇKKV sonuçlarına göre ilk sırada yer alan toplu taşıma sistemi ekonomik-mali fizibilite etüdlerinde uygulanabilir sonuçlar vermiyorsa, ikinci sıradaki toplu taşıma sistemi için aynı işlemler tekrarlanabilir. ÇKKV'de en yüksek sıralamada olan ve ekonomik-mali fizibilite etüdünde uygulanabilir sonuç 
veren toplu taşıma sisteminin seçilmesi en uygun yöntem olabilir. ÇKKV ve ekonomik-mali fizibilite etüdünün bütüncül yaklaşımı bu şekilde yapılabilir.

\section{Sonuç}

$\mathrm{Bu}$ çalışmada monoray sisteminin raylı sistemlere alternatif olma durumu çok kriterli karar verme yöntemleri ve fizibilite çalışmaları birlikte ele alınarak incelenmiştir. ÇKKV'den PROMETHEE yöntemi kullanılmıştır. Alternatifler monoray ve raylı sistemlerden tramvay, hafif raylı sistem ve metro olarak belirlenmiştir. Kriterler dört ana kriter ve 11 alt kriterden oluşturulmuştur. Eskişehir için tramvayın yeterli hizmet düzeyine sahip olmadığı SSK-Otogar ve tramvay yapımı devam eden Gaffar Okkan-ESTÜ hattı için yapılan monoray fizibilite etüdü çalışmasının sonuçları da ele alınarak ÇKKV-fizibilite ilişkisi incelenmiştir. Monorayın raylı sistemlere alternatif olabilirliği ÇKKV-fizibiliteye göre bütüncül yaklaşımla ele alınmıştır. Yapılan PROMETHEE ve fizibilite değerlendirmelerine göre aşağıdaki sonuçlar çıkarılabilir.

Çalışmada elde edilen sonuçlara birinci sırada monoray sistemi yer almaktadır. Monoray sisteminin sahip olduğu üstün özellikler raylı sisteme alternatif bir sistem olabileceğini göstermektedir. Monoray uygulamada en iyi sistem görünmesine rağmen yapılan monoray sistemi ekonomik-mali fizibilite etüdünde uygulanabilir sonuçlar alınmamıştır. Ekonomik-mali fizibilite etüdlerinde düşük yapım maliyeti sebebiyle uygulanabilir sonuçlar veren ve birçok belediye tarafindan tercih edilen tramvay sistemi ise PROMETHEE yönteminde en son sirada kalmaktadır. Bu bulgular ÇKKV veya fizibilite etütlerinin tek başına toplu taşıma sistemi seçimi ve planlanmasında yeterli olmayacağını, ikisinin beraber değerlendirilerek optimum sistemin seçilmesi gerektiğini gösterebilir. ÇKKV'ye göre nitel kriterlerde ele alınarak toplu taşıma sistemlerin en iyiden en kötüye sıralanması, bu sıralamaya göre ekonomik-mali fizibilite etüdlerinin yapılarak uygulanabilir sonuç veren ilk toplu taşıma sistemin seçilmesi uygun bir çözüm olabilir. $\mathrm{Bu}$ yaklaşımla toplu taşımanın istenilen düzeyde kullanımı ve otomobil kullanımının azatılması sağlanabilir. Bu çalışmada kriterler eşit öneme sahip olarak uygulama yapılmıştır. Karar verici kurum/belediyelerin yolcuların ihtiyaç ve beklentilere uygun olarak kriter ağırlıklarını belirlemeleri daha verimli sonuçlar alınmasını sağlayabilir.

Gelecekteki çalışmalarda, farklı ÇKKV yöntemleri, daha geniş bir toplu taşıma sistemi yelpazesi ve farklı şehir ölçekleri düşünülebilir.

\section{Kaynakça}

[1] G. Qiu, R. Song, ve S. He, "The aggravation of urban air quality deterioration due to urbanization, transportation and economic development - Panel models with marginal effect analyses across China", Science of The Total Environment, c. 651, ss. 1114-1125, Feb. 2019, doi: 10.1016/j.scitotenv.2018.09.219.

[2] J. A. Manzolli, J. P. Trovão, ve C. H. Antunes, "Scenario-Based Multi-criteria decision analysis for rapid transit systems implementation in an urban context", eTransportation, c. 7, s. 100101, Feb. 2021, doi: 10.1016/j.etran.2020.100101.

[3] B. Lin ve Z. Du, "Can urban rail transit curb automobile energy consumption?", Energy Policy, c. 105, ss. 120-127, June. 2017, doi: 10.1016/j.enpol.2017.02.038.

[4] A. S. Bergantino, M. Intini, ve L. Tangari, "Influencing factors for potential bike-sharing users: an empirical analysis during the COVID-19 pandemic", Research in Transportation Economics, c. 86, s. 101028, May. 2021, doi: 10.1016/j.retrec.2020.101028.

[5] F. Yıldızhan, "Monoray sisteminin Eskişehir'de uygulanabilirliğinin araştırılması", Yüksek lisans tezi, İnşaat mühendisliği bölümü, Eskişehir Osmangazi Üniversitesi, Eskişehir, 2019.

[6] İ. H. Acar, "Bütünleşik Ulaşım Politikası ve Avrupa Kentsel Şartı, Ulaşım ve Dolaşım İlkeleri", TMMOB Ulaştırma Politikaları Kongresi, Ankara, 2003, ss. 41-59.

[7] P. Yalınız ve Ş.Bilgiç, "Eskişehir Kent Merkezinde 'Park Et ve Bin' Uygulamasının Sürdürülebilir Ulaştırma Bağlamında Değerlendirilmesi”, 7. Ulaştırma Kongresi, İstanbul, 2007, ss. 461-470. 
[8] S. Gössling, "Integrating e-scooters in urban transportation: Problems, policies, and the prospect of system change", Transportation Research Part D: Transport and Environment, c. 79, s. 102230, Feb. 2020, doi: 10.1016/j.trd.2020.102230.

[9] S. Grava, Urban Transportation Systems. Choices for Communities. McGraw-Hill, United States 2003.

[10] H. Liu, W. Y. Szeto, ve J. Long, "Bike network design problem with a path-size logit-based equilibrium constraint: Formulation, global optimization, and matheuristic", Transportation Research Part E: Logistics and Transportation Review, c. 127, ss. 284-307, July. 2019, doi: 10.1016/j.tre.2019.05.010.

[11] D. Pojani ve D. Stead, Ed., The Urban Transport Crisis in Emerging Economies. Springer International Publishing, 2017.

[12] R. G. Mugion, M. Toni, H. Raharjo, L. D. Pietro, ve S. P. Sebathu, "Does the service quality of urban public transport enhance sustainable mobility?", Journal of Cleaner Production, c. 174, ss. 15661587, Feb. 2018, doi: 10.1016/j.jclepro.2017.11.052.

[13] J. B. Ingvardson ve O. A. Nielsen, "Effects of new bus and rail rapid transit systems - an international review", Transport Reviews, c. 38, sy 1, ss. 96-116, Jan. 2018, doi: 10.1080/01441647.2017.1301594.

[14] F. Proboste, J. C. Muñoz, ve A. Gschwender, "Comparing social costs of public transport networks structured around an Open and Closed BRT corridor in medium sized cities", Transportation Research Part A: Policy and Practice, c. 138, ss. 187-212, Aug. 2020, doi: 10.1016/j.tra.2020.06.005.

[15] M. Rizelioğlu, "Bursa hrs hattının metrobüs sistemi olarak modellenmesi”, Yüksek lisans tezi, İnşaat mühendisliği bölümü, Uludağ Üniversitesi, Bursa, 2015.

[16] V. R. Vuchic, Urban Transit Systems and Technology. John Wiley \& Sons, 2007.

[17] F. Yildizhan ve M. Karacasu, "Monorail System Feasibility Study for Developing Countries: The Case Study of Eskişehir-Turkey”, Politeknik Dergisi, (Baskıda), doi: 10.2339/politeknik.814239.

[18] P. E. Timan, "Why Monorail Systems Provide a Great Solution for Metropolitan Areas", Urban Rail Transit, c. 1, sy 1, ss. 13-25, March. 2015, doi: 10.1007/s40864-015-0001-1.

[19] E. Memiş, "Monoray sistemleri, Türkiye'deki yatırım süreçleri ve yerel yönetimlerin monoraya yaklaşımı”, Yüksek lisans tezi, İnşaat mühendisliği bölümü, İstanbul Teknik Üniversitesi, İstanbul, 2016.

[20] T. Kuwabara, M. Hiraishi, K. Goda, S. Okamoto, A. Ito, ve Y. Sugita, "New Solution for Urban Traffic: Small-Type Monorail System”, Automated People Movers 2005: Moving to Mainstream, ss. 1-7, April. 2012, doi: 10.1061/40766(174)65.

[21] M. Hamurcu ve T. Eren, "Monoray ve Türkiye'de Potansiyel Uygulanabilirliği”, Transist 8. Uluslararası Ulaşım Teknolojileri Sempozyumu ve Fuarı, İstanbul, 2015.

[22] E. A. Çalis, "Monoray ulasim sisteminin özellikleri ve diğer kentiçi ulasim araçlari ile karsilastirilmasi”, Yüksek lisans tezi, İnşaat mühendisliği bölümü, İstanbul Teknik Üniversitesi, İstanbul, 2016.

[23] İ. H. Acar, "Trafik ve Ulaşım Konularında Kanılar ve Gerçekler”, 7. Ulaştırma Kongresi, Kongre Sempozyum Bildiriler Kitab1, 2007, ss. 23-34.

[24] M. Rizelioğlu ve T. Arslan, "A comparison of LRT with an imaginary BRT system in performance: Bursa example", Case Studies on Transport Policy, c. 8, sy 1, ss. 135-142, March. 2020, doi: 10.1016/j.cstp.2019.01.007.

[25] Ö. Atik, "Lastik ve çelik alaşım tekerlekli metro araçlarının taşıma maliyetleri analizi ve karşılaştırılması”, Yüksek lisans tezi, İnşaat mühendisliği bölümü, Yıldız Teknik Üniversitesi, İstanbul, 2010.

[26] D.-J. Lee, "A multi-criteria approach for prioritizing advanced public transport modes (APTM) considering urban types in Korea", Transportation Research Part A: Policy and Practice, c. 111, ss. 148-161, May. 2018, doi: 10.1016/j.tra.2018.02.005.

[27] D. Browne ve L. Ryan, "Comparative analysis of evaluation techniques for transport policies", Environmental Impact Assessment Review, c. 31, sy 3, ss. 226-233, April. 2011, doi: 10.1016/j.eiar.2010.11.001.

[28] P. Delle Site ve F. Filippi, "Weighting methods in multi-attribute assessment of transport projects", Eur. Transp. Res. Rev., c. 1, sy 4, ss. 199-206, Dec. 2009, doi: 10.1007/s12544-009-0018-1.

[29] H. Bağcı ve Ö. F. Rençber, "Kamu Bankaları ve Halka Açık Özel Bankaların Promethee Yöntemi İle Kârlılıklarının Analizi”, Aksaray Üniversitesi Iktisadi ve İdari Bilimler Fakültesi Dergisi, c. 6, sy 1,ss. 39-47 Oca. 2014. 
[30] X. He, “Application and Prospect of Straddle Monorail Transit System in China”, Urban Rail Transit, c. 1, sy 1, ss. 26-34, March. 2015, doi: 10.1007/s40864-015-0006-9.

[31] T. Sekitani, M. Hiraishi, S. Yamasaki, ve T. Tamotsu, "China's first urban monorail system in Chongqing”, Hitachi Review, c. 54, ss. 193-197, Dec. 2005.

[32] D. Pan, L. Zhao, Q. Luo, C. Zhang, ve Z. Chen, "Study on the performance improvement of urban rail transit system", Energy, c. 161, ss. 1154-1171, Oct. 2018, doi: 10.1016/j.energy.2018.07.067.

[33] G. Akman ve A. Alkan, "İzmit kent içi ulaşımda alternatif toplu taşıma sistemlerinin aksiyomlarla tasarım yöntemi ile değerlendirilmesi”, Pamukkale Üniversitesi Mühendislik Bilimleri Dergisi, c. 22, sy 1, ss. 54-63, 1, Şub. 2016, doi: 10.5505/pajes.2015.55376.

[34] B. Birol, "Kentiçi raylı sistemler ve metrobüs işletme maliyeti değerlendirilmesi: İstanbul Örneği”, Yüksek lisans tezi, İnşaat mühendisliği bölümü, İstanbul Teknik Üniversitesi, İstanbul, 2014.

[35] P. Miller, S. C. Wirasinghe, L. Kattan, ve A. De Barros, "Monorails for sustainable transportation a review", CSCE 2014 General Conference, Halifax, 2014.

[36] M. Hamurcu ve T. Eren, Toplu Taşıma Türünün Seçiminde Çok Kriterli Karar Verme Uygulaması. International Conference on Advanced Engineering Technologies (ICADET), Bayburt, 2017.

[37] Japan Monorail Association, "Monorails", 2019. [Online]. Available: http://www.nihonmonorail.or.jp/assets/pdf/2019english.pdf. [Accessed: 29-Nov-2021].

[38] D. A. Manoratna, K. Kawata, ve Y. Yoshida, "Environmental impact and travel time savings of a new monorail system in colombo's commuting traffic", Transportation Research Part D: Transport and Environment, c. 51, ss. 122-128, March. 2017, doi: 10.1016/j.trd.2016.12.003.
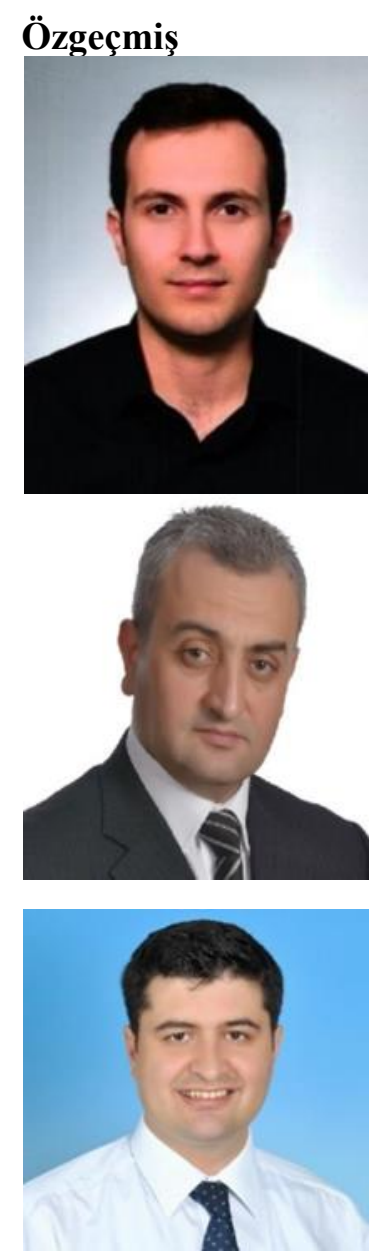

\section{Beyanlar:}

\section{Fatih YILDIZHAN}

Lisans eğitimini Anadolu Üniversitesi İnşaat Mühendisliğinde, yüksek lisans eğitimini Eskişehir Osmangazi Üniversitesi İnşaat Mühendisliği Ulaştırma Anabilim Dalında tamamlamıştır. Şuan Gaziantep Üniversitesinde doktora yapmakta ve ulaştırma anabilim dalında araştırma görevlisi olarak çalışmaktadır. İlgi alanına giren araştırma konuları kent içi ulaşım sistemleri ve ulaştırma ekonomisidir.

E-Posta: fyildizhan@gantep.edu.tr

\section{Murat KARACASU}

Lisans eğitimini Eskişehir Osmangazi Üniversitesi İnşaat Mühendisliğinde, doktora eğitimini İstanbul Teknik Üniversitesi Ulaştırma Anabilim Dalında tamamlamıştır. Halen Eskişehir Osmangazi Üniversitesi, İnşaat Mühendisliği Bölümü, Ulaştırma Anabilim Dalı başkanı olarak, Prof. Dr. ünvanı ile çalışmaktadır. Araştırma konuları asfalt betonu, atık ve modelleme üzerinedir.

E-Posta: muratk@ogu.edu.tr

\section{Ömer Faruk RENÇBER}

Lisans eğitimini Niğde Üniversitesi FEF Matematik bölümünde, yüksek lisans eğitimini Gebze Teknik Üniversitesi SBE İşletme ABD'da ve Doktora eğitimini Aksaray Üniversitesi SBE İşletme ABD'da tamamlamıştır. Şu an aktif olarak Gaziantep Üniversitesi İ̈BF İşletme Bölümünde öğretim üyesi olarak görevine devam etmektedir. Çalışma alanı, istatistik, veri madenciliği ve çok kriterli karar verme teknikleridir.

E-Posta: ofrencber@gantep.edu.tr

(us makalede bilimsel araştırma ve yayın etiğine uyulmuştur

Yazarların katkıları: Yazar katkıları belirtilmemiştir. 